\title{
RHEUMATOID ARTHRITIS EDUCATIONAL GROUPS - REMOTE MONITORING DURING THE COVID-19 PANDEMIC
}

Anderson Ramos Lisboa ${ }^{1}$, Fernanda Danielle Silva Oliveira ${ }^{1}$, Ana Leticia Fontes de Oliveira Marcelino ${ }^{1}$, João Victor de Pinho Costa $^{1}$, Caio Carvalhais Chaves ${ }^{1}$, Urias Paulo Furquim Junior ${ }^{2}$, Tamires Rodrigues Pimentel da Silva ${ }^{1}$, Vivian Guerra de Faria ${ }^{1}$, Laura Cristine Carmo da Silva ${ }^{1}$, Liliane Morais Amaral ${ }^{1}$, Junia Amorim Andrade ${ }^{1}$, Ricardo Cruz Lage ${ }^{1}$, Maria Raquel da Costa Pinto $^{1}$, Maria Fernanda Brandao Resende Guimaraes ${ }^{1}$, Adriana Maria Kakehasi ${ }^{1}$, Débora Cerqueira Calderaro ${ }^{1, *}$

1.Universidade Federal de Minas Gerais, Belo Horizonte (MG), Brazil. 2. Universidade Estadual do Rio de Janeiro, Rio de Janeiro (RJ), Brazil. *Corresponding author: dccalderaro@gmail.com

\section{BACKGROUND}

Rheumatoid arthritis (RA) patients may have disabilities and reduced quality of life, associated with joint pain and deformities caused by the disease. Occupational therapy (OT) interventions focused on energy conservation (EC) and joint protection (JP) might help to decrease symptoms and delay disease evolution. Education groups for RA patients addressing issues on RA nature and course and EC and JP interventions are conducted in the rheumatology department of a university hospital since 2018. During the COVID-19 pandemic, these groups' encounters were suspended. They were then reformulated and performed by telephone contacts with these patients.

\section{MATERIALS AND METHODS}

When in-person meetings of RA patients' groups were suspended, a standardized questionnaire was developed and applied via phone call to reinforce techniques and advises suggested in previous and ongoing groups, besides evaluating the impact of COVID-19 pandemic on the routine of these patients. This questionnaire addresses patients' impressions about their health and treatment, the practice of $\mathrm{EC}$ and JP interventions, and the impact of the pandemic on their routine. The EuroQoL-5D-3L quality of life questionnaire was also applied. These patients' doubts that emerged during the phone contact were elucidated.

\section{RESULTS}

This work presents data from 11 (91\% female) RA patients contacted in July 2020. They had an average age (SD): 62.8 (9.05) years. All were on social distancing and reported fear of contracting COVID-19. Seven (64\%) patients reported suspension/reduction in the frequency of medical appointments and exams; 9 (82\%) had physiotherapy or OT consultations suspended; 4 (36\%) interrupted EC and JC measures. Nine (82\%) patients reported worsening joint pain. In EuroQoL - 5D-3L, most patients did not describe motility $(64 \%)$ or personal care (91\%) problems; $55 \%$ had some difficulty carrying out their usual activities; all reported moderate (82\%) to extreme (18\%) pain/malaise; and some complained of moderate (27\%) to extreme (27\%) anxiety/depression (Fig. 1).

\section{CONCLUSIONS}

During the COVID-19 pandemic, patients with RA experienced worsening of pain, possibly associated with interruption/reduction of health care and rehabilitation. This worsening could also be associated with the uncertainties of this moment when all patients described fear of COVID-19 and the majority reported moderate to extreme anxiety/depression. The remote monitoring allowed patients to keep techniques taught by the multidisciplinary team and, in addition, allowed students and professionals to experience new forms of assistance and a better understanding of the patients' routine.

\section{ACKNOWLEDEGMENTS}

We thank the multidisciplinary team at the Clinics Hospital of the Federal University of Minas Gerais (EBSerH/HC-UFMG) for their support. 


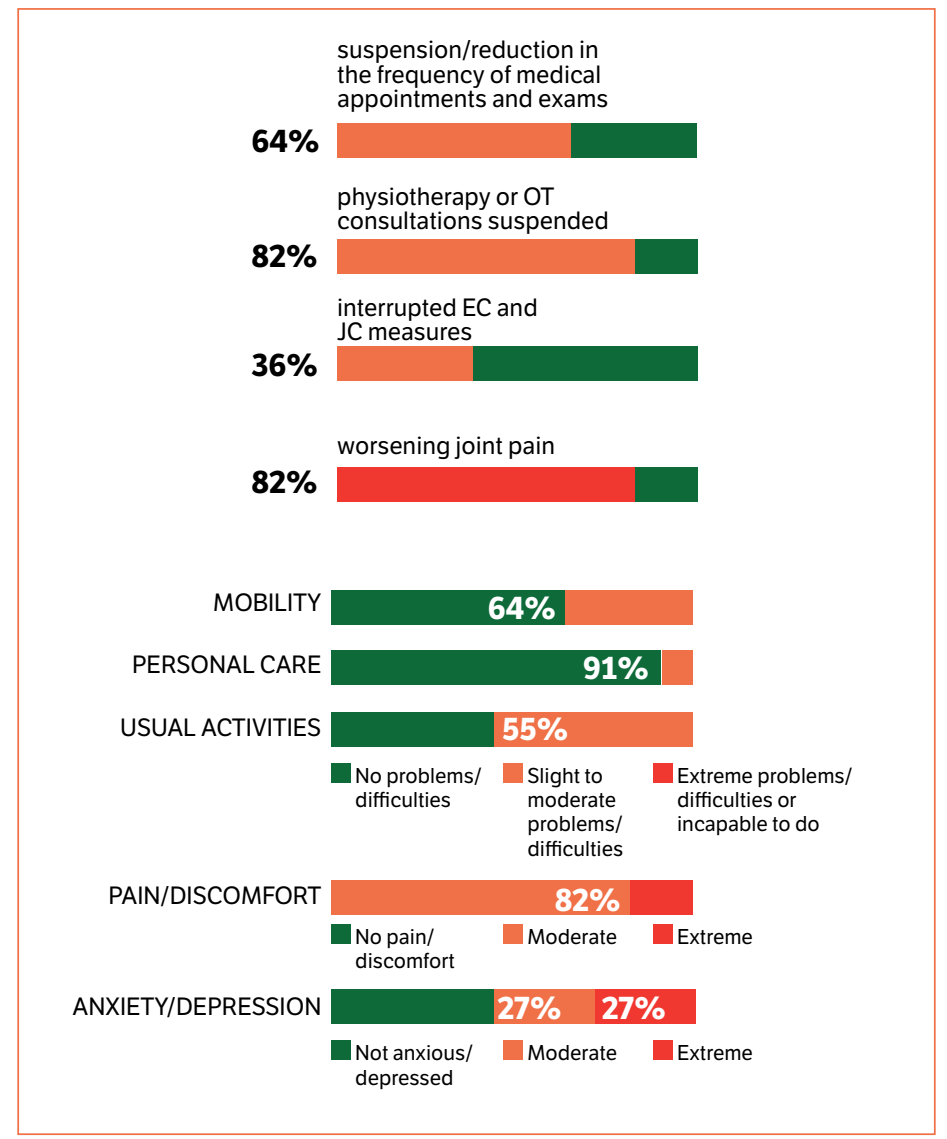

Figure 1. Summary of the main findings of this study.

\section{FUNDING}

Programa de Apoio a Doutores recém-contratados 2019 - Universidade Federal de Minas Gerais

\section{REFERENCES}

Torquetti A, Campos TS, Noordhoek J Cassiano J.G. Programas de proteção articular para indivíduos com artrite reumatóide: uma revisão da literatura. Rev Ter Ocup Univ São Paulo. 2008;19(2):76-84. https://doi.org/10.11606/issn.2238-6149.v19i2p76-84

Loschiavo F, Noordhock J. Intervenção de terapia ocupacional no tratamento de indivíduos com doenças reumáticas utilizando a abordagem de proteção articular. Rev Bras Reumatol. 2005;45(4):242-44. https://doi.org/10.1590/S0482-50042005000400008 